\title{
Rancang Bangun Klinometer Sebagai Pendukung Praktikum Fisika Kelautan dan Geofisika
}

\author{
Haidul ${ }^{1}$ \\ 1Jurusan Fisika, Universitas Bengkulu, Bengkulu 38371 haidulyadip@gmail.com \\ Submisi: 5 Meret 2021; Penerimaan: 17 April 2021
}

\begin{abstract}
ABSTRAK
Telah dilakukan penelitian rancang bangun klinometer analog untuk menunjang pelaksanaan praktikum khususnya fisika kelautan dan geofisika di program studi fisika FMIPA Universitas Bengkulu. Klinometer yang telah dirancang menggunakan prinsip bandul yang tegak lurus terhadap bidang datar. Sudut kemiringan ditentukan dari sudut antara garis tegak lurus dengan tali gantungan bandul yang dapat dilihat pada busur derajat. Untuk mengindera tiang berskala sebagai patokan objek, digunakan teropong dan laser agar penginderaan objek menjadi akurat. Klinometer rancangan dikalibrasi terhadap klinometer standar merk Suunto Tandem. Kalibrasi dilakukan untuk berbagai variasi sudut kemiringan dengan persentase error ratarata sebesar 3,24\%. Pengujian klinometer rancangan dilakukan untuk mengetahui akurasi alat dengan variasi panjang lereng. Berdasarkan hasil pengujian diperoleh nilai persentase error rata-rata 2,06\% pada panjang lereng $50 \mathrm{~m}$ serta $4,37 \%$ pada panjang lereng $100 \mathrm{~m}$
\end{abstract}

Kata kunci : Rancang bangun; Klinometer; Analog; Teropong; Laser

\section{PENDAHULUAN}

Klinometer merupakan alat untuk mengukur sudut elevasi yang dibentuk antara garis datar dengan sebuah garis yang menghubungkan sebuah titik pada garis datar tersebut dengan titik puncak suatu objek (Syahrudi, 2019). Data elevasi maupun kemiringan sangat dibutuhkan dalam berbagai bidang. Dalam bidang transportasi, kemiringan lambung kapal, sayap serta badan pesawat terbang harus diketahui secara teliti agar resiko kecelakaan dapat diantisipasi (Warsito, 2011). Hasriyanti, 2019, melakukan karakteristik wilayah wisata permandian dengan parameter kemiringan serta kedalaman wilayah. Dalam bidang geofisika, geologi, kelautan, klinometer sangat dibutuhkan dalam menentukan elevasi maupun kemiringan suatu wilayah (Sari dkk, 2020). Fitri, 2019 melakukan evaluasi terhadap daya dukung lahan untuk keperluan hutan pertanian dengan memanfaatkan klinometer sebagai alat ukur kemiringan lahan. Sari D R, 2018 melakukan analisis waktu kerja pengukuran tinggi pohon menggunakan klinometer dan hagameter. Penelitiannya menghasilkan sebuah kesimpulan bahwa klinometer memiliki kelebihan lebih cepat dalam mengukur ketinggian pohon dibandingkan jika menggunakan hagameter. Dalam pembelajaran trigonometri, Sultoni, 2018 telah melakukan penelitian efektifitas penggunaan klinometer untuk pengukuran tinggi suatu objek. Dari hasil penelitiannya dapat disimpulkan bahwa klinometer efektif dalam mengukur tinggi objek. Klinometer juga digunakan dalam menentukan strike dan dip pada survey geologi (Wahyuni dkk, 2019)

Dalam pengukuran kemiringan, klinometer yang digunakan dapat berupa 
klinometer digital maupun analog dengan berbagai spesifikasi yang berbeda. Klinometer digital maupun analog memiliki kelebihan dan kekurangannya masing-masing. Klinometer digital umumnya lebih presisi dan akurat dibandingkan klinometer analog. Hal ini disebabkan oleh semakin berkembang pesatnya sensordengan ketelitian tinggi yang digunakan dalam penentuan sudut kemiringan. Klinometer analog umumnya memiliki ketahanan dalam durasi pemakaian serta lebih mudah dalam hal perawatan.

Syahrudi, 2019, telah merancang klinometer sederhana menggunakan pipa PVC dan busur derajat. Klinometer menggunakan sensor optik untuk mengukur tingkat kemiringan suatu objek telah didesain oleh (Warsito, 2011). Sistem terdiri dari sistem optik, sistem mekanik dan pengkondisi sinyal. Suhanto, 2019 membuat prototype klinemeter berbasis mikrokontroler serta menggunakan sensor akselometer dalam penentuan sudut. Dhamayanti, 2015, merancang teknologi kompas digital dan klinometer yang dapat mengukur berbagai variabel dalam survey geologi.

Ketersedian klinometer merupakan faktor penting dalam menunjang pelaksanaan pengukuran kemiringan baik untuk keperluan survey, penelitian maupun praktikum mahasiswa. Faktor harga yang relatif mahal serta perawatan dan perbaikan yang tidak mudah menjadi pertimbangan dalam pengembangan klinometer kedepannya. Program studi fisika FMIPA Universitas Bengkulu banyak membutuhkan klinometer dalam pelaksanaan praktikum untuk pengukuran elevasi maupun kemiringan suatu wilayah khususnya untuk mata praktikum bidang minat fisika kelautan dan geofisika. Kegiatan praktikum yang menggunakan klinometer di program studi Fisika FMIPA Universitas Bengkulu diantaranya yaitu : 1. Penentuan Laju Abrasi Pantai, 2. Pengukuran Tinggi Gelombang; 3. Analisis Pasang Surut Air Laut; 4. Penentuan Kemiringan Lereng; 5. Survey Air Tanah. Selama ini praktikum tersebut menggunakan klinometer Suunto Tandem yang jumlahnya terbatas. Ketersedian alat yang memiliki presisi dan akurasi yang tinggi serta mudah dalam perawatan dan perbaikan masih menjadi permasalahan yang dihadapai oleh program studi fisika FMIPA Universitas Bengkulu. Maka pada penelitian ini akan dirancang klinometer analaog dengan pengembangan alat pengindera dan laser untuk mendapatkan data sudut kemiringan yang akurat dan presisi.

\section{METODOLOGI}

\section{Bahan dan Alat Penelitian}

Perancangan klinometer menggunakan alat dan bahan yaitu tripod sebagai penyangga, Tiang berskala sebagai alat untuk menentukan tinggi, Busur diameter $50 \mathrm{~cm}$ sebagai alat pengukur sudut, laser dan teropong sebagai alat untuk penunjuk posisi pada tiang berskala (Gambar 1.a).

\section{Desain Klinometer}

Rancangan mekanis klinometer analog pada penelitian ini dapat dilihat pada gambar 1.b. Penentuan sudut kemiringan pada klinometer analog sangat bergantung pada ketelitian operator yang mengindera objek. Maka diperlukan teropong serta laser sebagai alat bantu untuk mengindera objek agar lebih teliti.

\section{Kalibrasi dan Pengujian Klinometer}

Data hasil pengukuran yang valid akan diperoleh dari alat ukur yang telah dikalibrasi. Klinometer yang dirancang dikalibrasi dengan cara menyamakan hasil ukur dengan klinometer standar 
yang presisi dan akurat. Klinometer standar dan akurat yang digunakan untuk mengkalibrasi yaitu klinometer merek Suunto Tandem dengan resolusi 0.5 derajat serta bekerja dengan baik pada rentang suhu $30^{\circ} \mathrm{C}-60^{\circ} \mathrm{C}$. Tingkat Presisi dan akurasi alat yang dirancang bergantung pada posisi dudukan busur, teropong dan laser yang dapat diatur sedemikian rupa sehingga data hasil pengukuran semakin mendekati data hasil pengukuran klinometer standar. Pengujian klinometer rancangan dilakukan pada berbagai tingkat kemiringan lereng dan panjang lereng yang berbeda yaitu untuk panjang lereng $50 \mathrm{~m}$ tingkat kemiringan klinometer standar adalah $6^{\circ}, 17,5^{\circ}$ dan $30^{\circ}$. Sedangkan untuk panjang lerenga $100 \mathrm{~m}$ tingkat kemiringannya adalah $70,15^{\circ}$ dan $31^{\circ}$. Selisih pengukuran antara kedua alat mendekati nol. Pengujian pada kemiringan yang berbeda dilakukan untuk mengetahui tingkat akurasi dan presisi busur sedangkan variasi jarak dilakukan untuk mengetahui visibilitas pembacaan tiang skala.
(3)

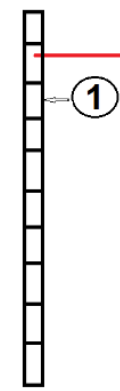

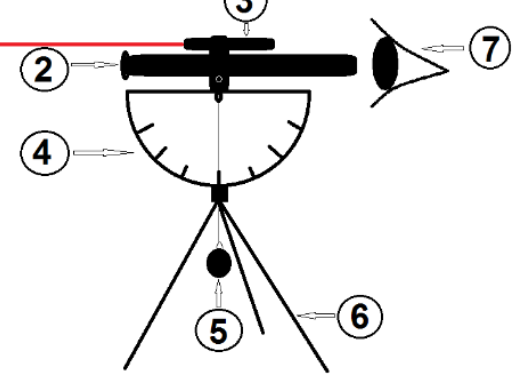

a

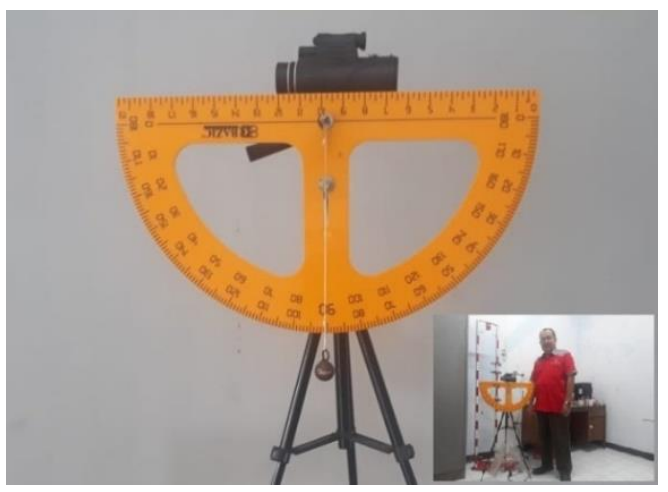

b
Keterangan Gambar :

1. Tiang bersakala

2. Teropong

3. Laser IR

4. Busur

5. Bandul

6. Tripod

Operator

Gambar 1.a. Desain Klinometer, b. Klinometer Rancangan

Tahapan pengujian secara rinci adalah sebagai berikut :

1. Persiapan klinometer satandar (Suunto Tandem), klinometer rancangan serta penentuan lokasi pengujian yang memungkinkan untuk mengindera pada jarak 100 $m$ serta memiliki tingkat kemiringan bervariasi.
2. Mengukur tingkat kemiringan lereng yang bervariasi menggunakan klinometer standar (Suunto Tandem) dan klinometer rancangan. Tingkat kemiringan lereng lokasi pengujian ialah $6^{0}$ hingga $31^{\circ}$ dengan panjang lereng $50 \mathrm{~m}$ dan $100 \mathrm{~m}$. 
3. Menghitung selisih rata-rata hasil pengukuran tingkat kemiringan dari klinometer standar (Suunto Tandem) dan klinometer hasil rancangan.

4. Klinometer rancangan akan semakin baik jika selisih rata-rata hasil pengukuran Klinometer standar (Suunto Tandem) dengan klinomter rancangan semakin mendekati 0 (nol).

\section{Analisis data}

Analisis yang dilakukan mengacu pada metode ADDIE (Analysis, Design, Development, Implementation and Evaluation). Pada penelitian ini, analisis data dilakukan secara kualitatif terhadap tahapan perancangan klinometer, kalibrasi serta data hasil pengujian klinometer yang telah dirancang.

\section{HASIL}

Klinometer yang telah dirancang menggunakan prinsip bandul yang tegak lurus terhadap bidang datar. Sudut kemiringan ditentukan dari sudut antara garis tegak lurus dengan tali gantungan bandul yang dapat dilihat pada busur derajat. Untuk mengindera tiang berskala sebagai patokan objek, digunakan teropong dan laser agar penginderaan objek menjadi akurat. Klinometer dilengkapi dengan tripod atau tiang penyangga (Gambar 1.b).

Klinometer dikalibrasi agar hasil pengukuran sama dengan hasil pengukuran menggunakan klinometer standar (Tabel 1). Kalibrasi klinometer rancangan dilakukan pada sudut kemiringan yang bervariasi dalam skala laboratorium.

Klinometer yang telah dikalibrasi kemudian dilakukan pengujian lapangan. Pengujian lapangan dilakukan untuk mengetahui akurasi klinometer rancangan dalam mengukur sudut kemiringan lereng. Pengukuran sudut kemiringan lereng dilakukan pada nilai sudut serta jarak atau panjang lereng yang bervariasi seperti yang disajikan dalam tabel 2 dan tabel 3 .

Data hasil pengukuran menggunakan klinometer rancangan yang telah diperoleh kemudian dihitung persentase error rata-rata. Presentasi error rata-rata menunjukkan selisih hasil pengukuran antara klinometer standar dengan klinometer rancangan.

Tabel 1. Data Kalibrasi Klinometer Rancangan (KR) terhadap Klinometer Standar (KS) pada kemiringan bervariasi.

\begin{tabular}{ccccc}
\hline No & $\begin{array}{c}\text { Sudut Kemiringan } \\
\text { menggunakan KS } \\
\text { (Derajat) }\end{array}$ & $\begin{array}{c}\text { Sudut Kemiringan } \\
\text { menggunakan KR } \\
\text { (Derajat) }\end{array}$ & $\begin{array}{c}\text { Selisih Hasil } \\
\text { Pengukuran } \\
\text { (Derajat) }\end{array}$ & $\begin{array}{c}\text { Error } \\
(\%)\end{array}$ \\
\hline 1 & 0,00 & 0,00 & 0,00 & 0,00 \\
2 & 10,50 & 10,00 & 0,50 & 4,76 \\
3 & 15,50 & 15,00 & 0,50 & 3,22 \\
4 & 22,00 & 21,00 & 1,00 & 4,54 \\
5 & 27,00 & 26,00 & 1,00 & 3,70 \\
\hline
\end{tabular}

Tabel 2. Data Pengujian Pengukuran Kemiringan dengan Panjang Lereng 50 m Klinometer Standar (KS) dan Klinometer Rancangan (KR).

\begin{tabular}{ccccc}
\hline No & $\begin{array}{c}\text { Sudut Kemiringan } \\
\text { menggunakan KS } \\
\text { (Derajat) }\end{array}$ & $\begin{array}{c}\text { Sudut Kemiringan } \\
\text { menggunakan KR } \\
\text { (Derajat) }\end{array}$ & $\begin{array}{c}\text { Selisih Hasil } \\
\text { Pengukuran } \\
\text { (Derajat) }\end{array}$ & $\begin{array}{c}\text { Error } \\
(\%)\end{array}$ \\
\hline 1 & 6,00 & 6,00 & 0,00 & 0,00 \\
2 & 17,50 & 17,00 & 0,50 & 2,86 \\
3 & 30,00 & 29,00 & 1,00 & 3,33 \\
\hline
\end{tabular}


Tabel 3. Data Pengujian Pengukuran Kemiringan dengan Panjang Lereng $100 \mathrm{~m}$ Klinometer Standar (KS) dan Klinometer Rancangan (KR).

\begin{tabular}{ccccc}
\hline No & $\begin{array}{c}\text { Sudut Kemiringan } \\
\text { menggunakan KS } \\
\text { (Derajat) }\end{array}$ & $\begin{array}{c}\text { Sudut Kemiringan } \\
\text { menggunakan KR } \\
\text { (Derajat) }\end{array}$ & $\begin{array}{c}\text { Selisih Hasil } \\
\text { Pengukuran } \\
\text { (Derajat) }\end{array}$ & $\begin{array}{c}\text { Error } \\
(\%)\end{array}$ \\
\hline 1 & 7,00 & 7,00 & 0,00 & 0,00 \\
2 & 15,00 & 14,00 & 1,00 & 6,67 \\
3 & 31,00 & 29,00 & 2,00 & 6,45 \\
& & Error rata-rata (\%) & 4,37 \\
\hline
\end{tabular}

\section{PEMBAHASAN}

Klinometer hasil rancangan pada penelitian ini merupakan klinometer analog menggunakan komponen atau bahan yang relatif mudah didapatkan, mudah dirancang serta mudah dalam penggunaan dan perawatan. Hal ini merupakan faktor penting mengatasi permasalahan ketersediaaan klinometer dalam menunjang kelancaran praktikum khususnya bidang fisika kelautan dan geofisika di program studi fisika FMIPA Universitas Bengkulu. Klinometer dirancang berdasarkan prinsip pendulum yang selalu tegak lurus terhadap bidang datar. Komponen atau bahan yang digunakan yaitu busur sebagai peraga sudut, bandul yang digantungkan pada busur sebagai penunjuk sudut, teropong dan laser sebagai alat pengindera objek berupa tiang berskala yang diatur tingginya sesuai dengan tinggi posisi klinometer, dan tiang penyangga sebagai dudukan klinometer. Pada penelitian ini, klinometer analog dikembangkan khususnya untuk meningkatkan akurasi penginderaan pengukuran sudut dengan menambahkan teropong dan laser (Gambar 1.b). Teropong dan laser berguna untuk memperjelas objek sehingga akan memperkecil kesalahan operator dalam mengindera objek khususnya pada jarak objek hingga 100 $\mathrm{m}$. Kesalahan operator dalam mengindera objek berpengaruh pada posisi gantungan bandul sebagai penunjuk sudut kemiringan.
Klinometer rancangan pada penelitian ini telah dikalibrasi dengan klinometer standar (Suunto Tandem). Kalibrasi dilakukan dengan tujuan untuk menyamakan hasil pengukuran dengan klinometer standar seperti yang disajikan pada tabel 1. Pada tabel 1 dapat dilihat bahwa hasil kalibrasi diperoleh pada 5 variasi nilai sudut kemiringan yaitu $0,00^{\circ}$, $10,50^{\circ}, 15,50^{\circ}, 22,00^{\circ}$, dan $27,00^{\circ}$. Berdasarkan data hasil kalibrasi dapat dijelaskan bahwa antara klinometer standar (Suunto) dengan klinometer yang dirancang memiliki selisih hasil pengukuran antara $0^{0}$ hingga $1^{0}$. Secara umum jika dihitung persentase error ratarata hasil pengukuran klinometer rancangan yaitu sebesar $3,24 \%$. Error hasil pengukuran menggunakan klinometer hasil rancangan dapat terjadi akibat kesalahan operator dalam mengindera objek atau tiang berskala. Salah satu cara untuk memperkecil kesalahan operator yaitu dengan cara melakukan pengukuran berulang kali dan ditentukan nilai rata-ratanya.

Pengujian klinometer rancangan yang telah dikalibrasi dilakukan untuk mengetahui akurasi alat di lapangan. Pengujian dilakukan khususnya untuk melihat akurasi alat pada panjang lereng yang bervarias (Tabel 2 dan Tabel 3 ). Pengujian lapangan dilakukan pada panjang lereng $50 \mathrm{~m}$ dan $100 \mathrm{~m}$. Sudut kemiringan bervariasi antara $6^{\circ}$ sampai dengan $31^{\circ}$. Berdasarkan tabel 2 dan tabel 3 dapat dijelaskan bahwa semakin 
panjang lereng yang akan diukur sudut kemiringannya maka nilai persentase error rata-rata klinometer rancangan semakin besar. Persentase error ratarata pada panjang lereng $50 \mathrm{~m}$ sebesar $2,06 \%$ sedangkan persentase error ratarata pada panjang lereng $100 \mathrm{~m}$ sebesar $4,37 \%$. Semakin besar persentase error rata-rata dengan bertambahnya panjang lereng atau jarak objek berkaitan dengan keakuratan penginderaan tiang berskala. Pada jarak yang semakin jauh maka akan semakin menurun akurasi alat pengindera berupa teropong serta laser. Berkas sinar laser akan semakin melebar dengan bertambahnya jarak. Untuk memperkecil persentase error rata-rata untuk panjang lereng yang semakin besar maka harus ditingkatkan kemampuan alat pengindera yaitu berupa teropong dan laser serta pengukuran yang berulang kali untuk memperkecil kesalahan operator.

Klinometer hasil rancangan memiliki beberapa kelebihan jika dibandingkan dengan klinometer standar yang umum digunakan. Kelebihan klinometer rancangan diantaranya adalah :

1. Biaya pembuatan relatif lebih rendah dibandingkan dengan klinometer standar (Suunto Tandem).

2. Perbaikan dan perawatan klinometer rancangan dapat dilakukan sendiri karena tidak diperlukan keterampilan atau keahlian khusus.

3. Klinometer rancangan sudah dilengkapi dengan teropong dan laser sebagai alat bantu untuk mengindera jarak yang relatif jauh hingga $100 \mathrm{~m}$.

4. Klinometer rancangan tidak bergantung pada suhu lingkungan.

\section{KESIMPULAN}

Klinometer yang dirancang dapat digunakan untuk mengukur sudut kemiringan suatu wilayah sebagai data penunjang praktikum geofisika dan fisika kelautan di program studi fisika, jurusan Fisika FMIPA Universitas Bengkulu. Klinometer yang telah dirancang memiliki error rata-rata sebesar $2,06 \%$ untuk jarak ukur $50 \mathrm{~m}, 4,37 \%$ untuk jarak ukur 100 $\mathrm{m}$. Untuk memperkecil error rata-rata maka pengembangan kedepan dapat diupayakan dengan cara meningkatkan spesifikasi ketajaman sinar laser serta kemampuan teropong sebagai alat pengindera.

\section{DAFTAR PUSTAKA}

Dhamayanti E, Alkatiri K Dan Riky Y, "Techno-Kompas" Teknologi Kompas Geologi Digital Dan Klinometer Serba Bisa Untuk Akuisisi Data Pengukuran StrikeDip Pada Bidang Geologi, Geofisika, Dan Arkeologi, Proceeding, Seminar Nasional Kebumian (2015), 8.

Fitri R, Nuraida, Rahmi R, Evaluation Of Land Capability For Agroforestry Development In Ciliwung Watershed, Jurnal Agrosains Dan Teknologi (2019), 4(1).

Hasriyanti, Ansarullah, Karakteristik Kemiringan Lereng, Kedalaman Dan Kecerahan Dalam Mendukung Aktivitas Permandian Di Pantai Marumasa Kecamatan Bontobahasi Kabupaten Bulukumba, Jurnal Environmental Science (2019), 2(1) 99 - 109.

Sari D R dan Ariyanto, Analisis Waktu Kerja Pengukuran Tinggi Pohon Menggunakan Klinometer Dan Hagameter, Jurnal Hutan Tropis (2018), 2(2) $79-84$.

Sari R I Dkk, Pengukuran Rekahan, Pada Batuan Sedimen Di Sungai Cipogo Padalarang Kabupaten Bandung Jawa Barat, Jurnal Buana (2020), 4(5) 954 - 964. 
Suhanto, Prototype Clinometer Digital sebagai Alat Kalibrasi Sudut Precision Approach Path Indicator, Jurnal Penelitian(2019), 4(1) 16 24.

Sultoni A, Pembelajaran Materi Trigonometri Menentukan Tinggi Suatu Benda Berbantuan Klinometer Fleksibel, Prosiding Seminar Nasional Matematika (2018), 1(1) $860-869$.

Syahrudi, Penggunaan Klinometer Sebagai Pendukung Penguatan Konsep Siswa Tentang Perbandingan Trigonometri,
Indonesian Digital Journal of Mathematics and Education (2019), 6(1) 612-619.

Wahyuni A Dkk, Pengukuran Strike Dan Dip Di Desa Padaelo Kecamatan Mallawa Kabupaten Maros Sulawesi Selatan, Jurnal Fisika Dan Terapannya (2019), 1(6) 89 93.

Warsito, Suciyati S W dan Fauzi $Y$, Desain Dan Analisis Alat Ukur Tingkat Kemiringan (Inclinometer) Suatu Objek Menggunakan Sensor Optik, J. Sains MIPA (2011), 17(2) $53-58$. 